\title{
TRANSFORMATION OF BACILLUS SUBTILIS, ANTIFUNGAL-ANTIBIOTIC ITURIN PRODUCERS WITH ISOLATED ANTIBIOTIC RESISTANCE PLASMIDS
}

\author{
YUKO MATSUNO, TATSUYA HITOMI, TAKASHI ANO,* \\ AND MAKOTO SHODA \\ Research Laboratory of Resources Utilization, Tokyo Institute of Technology, \\ 4259 Nagatsuta, Midori-ku, Yokohama 227, Japan *
}

(Received September 27, 1991)

In order to obtain appropriate vectors to transform several strains of Bacillus subtilis, antifungal iturin producers, plasmids have been isolated as covalently closed circular deoxyribonucleic acid from antibioticresistant bacteria inhabited in composts. Eight plasmids coding antibiotic resistance transformed both competent cells of a derivative of $B$. subtilis Marburg 168 and protoplasts of $B$. subtilis NB22, an antifungal-antibiotic iturin producer, in the presence of polyethylene glycol. However, transformation efficiency was not high enough as a cloning host-vector system. To improve transformation efficiency, KCl-treatment method and electroporation method were applied to four iturin producers, and electroporation method was most effective for transformation with newly-isolated plasmids with great efficiency.

We have demonstrated that several strains of Bacillus subtilis isolated from composts showed broad suppressive spectra on various plant pathogens by producing an antibiotic, iturin extracellularly $(19,20)$. These iturin-producing strains can be candidates of biological control agent to minimize the use of chemical pesticides (19-21).

Iturin is a group of peptidolipidic antibiotics which is characterized by the presence of $\beta$-amino acid linked to a peptide moiety containing 7 residues of $L$ - and, D- $\alpha$-amino acids giving a cyclic structure $(11,18,24)$. The application of genetic engineering to these antibiotic-producing strains might lead to enhanced productivity of the antibiotics and also to biosynthesis of novel antibiotics by modification of the structure of the iturin.

* Address reprint requests to: Dr. Takashi Ano, Research Laboratory of Resources Utilization, Tokyo Institute of Technology, 4259 Nagatsuta, Midori-ku, Yokohama 227, Japan. 
Cloning and functional study of antibiotic producing genes must largely be done within the microorganisms in which the genes are originated rather than in Escherichia coli, because antibiotic biosynthesis is carried out through physiologically, biochemically and genetically complex manners inherited in the original strains. Thus, establishment of host-vector system in antibiotic-producing strain is a prerequisite for cloning antibiotic production gene(s).

This paper describes the isolation of vector plasmids from bacteria inhabiting in composts and the comparison of transformation efficiencies of iturin-producing bacteria with the plasmids isolated by three different transformation methods i.e. protoplast, $\mathrm{KCl}$ and electroporation methods.

\section{MATERIALS AND METHODS}

Bacterial strains and plasmids. As a recipient strain for plasmid screening, $B$. subtilis MI113 (arg-15 trpC2 hsmM hsrM), which is a derivative of B. subtilis Marburg 168, was used. B. subtilis NB22, UB24, YB8 $(19,20)$, and RB14 (this work) are iturin-producing strains originally isolated from different composts in this laboratory. These four bacterial strains were different from each other in the degree of suppressiveness to plant pathogens and in cultural characteristics (20). Plasmid pC194 (7) which is specified by the resistance to chloramphenicol was used as a control plasmid.

Culture media and growth condition. L medium, containing $10 \mathrm{~g}$ of Polypepton, $5 \mathrm{~g}$ of yeast extract, and $5 \mathrm{~g}$ of $\mathrm{NaCl}$ in one liter of distilled water (pH 7.2 adjusted with $\mathrm{NaOH}$ ), was used. L medium was solidified with $15 \mathrm{~g}$ of agar per liter to make L-agar plates.

Isolation of antibiotic-resistant bacteria. Antibiotic-resistant bacteria were isolated at $37^{\circ} \mathrm{C}$ from several kinds of composts on $\mathrm{L}$ agar containing one of the following antibiotics: chloramphenicol, erythromycin, kanamycin sulphate, streptomycin sulphate, tetracycline (each at $5 \mu \mathrm{g} / \mathrm{ml}$ ).

Preparation of plasmid DNAs. Plasmid DNAs were prepared from the bacteria grown in $\mathrm{L}$ medium containing each antibiotic by the alkaline lysis procedure (3) for small-scale preparation. For large-scale preparation, plasmids isolated by the alkaline lysis method were purified further by cesium chloride-ethidium bromide $(\mathrm{EtBr})$ density gradient centrifugation (15). All the plasmids used in this experiment were prepared from transformants of $B$. subtilis MI113.

Plasmid transformation. Competent cells of $B$. subtilis MI113 were prepared by the method described previously (1). Selection for antibiotic resistance was carried out after $2 \mathrm{~h}$ gene expression at $37^{\circ} \mathrm{C}$ by spreading the culture on $\mathrm{L}$ agar containing an antibiotic. Selective concentrations of antibiotics were: chloramphenicol [Cm], $5 \mu \mathrm{g} / \mathrm{ml}$; erythromycin [Em], $5 \mu \mathrm{g} / \mathrm{ml}$; kanamycin, $5 \mu \mathrm{g} / \mathrm{ml}$; tetracycline [Tc], $20 \mu \mathrm{g} / \mathrm{ml}$.

B. subtilis NB22 was transformed with plasmids by the protoplast transformation procedure (10), which is a modified method of the originally reported one 
by Chang and Cohen (4). For direct selection of transformants, the following concentrations of antibiotics were added into regeneration agar, respectively: $\mathrm{Cm}$, $20 \mu \mathrm{g} / \mathrm{ml}, \mathrm{Em}, 20 \mu \mathrm{g} / \mathrm{ml}, \mathrm{Tc}, 25 \mu \mathrm{g} / \mathrm{ml}$. Transformation frequency was scored after incubation of the protoplasts at $37^{\circ} \mathrm{C}$ for 2 days.

Transformation by $\mathrm{KCl}$-treatment method was performed according to our previous paper (2). The cells of $B$. subtilis grown in $\mathrm{L}$ medium to the middle logarithmic phase were harvested by centrifugation and washed twice with TE buffer ( $10 \mathrm{~mm}$ Tris-1 mM EDTA, pH 7.5), followed by the treatment with $4.1 \mathrm{M}$ $\mathrm{KCl}$ solution. Transformation was done in the presence of plasmid DNA and $35 \%$ polyethylene glycol (PEG) 6000, and the transformants were counted on the selective plates.

Transformation by electroporation was carried out using the Cell Porator linked to the booster (BRL Life Technologies, Inc., Gaithersburg, MD, U.S.A.) with $0.15 \mathrm{~cm}$ cuvette. The optimized procedure by electroporation is as follows (14). Cells of a $150 \mathrm{ml}$ late logarithmic growth phase culture of $B$. subtilis grown in $\mathrm{L}$ broth were harvested by centrifugation and washed three times with cold $\left(4^{\circ} \mathrm{C}\right) 1 \mathrm{~mm}$ Hepes ( $N$-2-hydroxyethylpiperazine- $N$-ethanesulfonic acid) buffer (pH 7.0) and were resuspended in a final volume of $400 \mu \mathrm{l}$ in the buffer. Aliquots $(40 \mu \mathrm{l})$ were mixed with $5 \mu \mathrm{l}$ of DNA and $40 \mu 1$ of $50 \%$ PEG 6000 in distilled water. From this mixture, $20 \mu 1$ were transferred to chilled cuvette $(0.15 \mathrm{~cm}$ electrode gap) and a single pulse of $16.0 \mathrm{kV} / \mathrm{cm}(2.4 \mathrm{kV}, 4 \mathrm{k} \Omega, 2 \mu \mathrm{F})$ was applied. Ten $\mu \mathrm{l}$ of this suspension were put into $0.5 \mathrm{ml}$ of $\mathrm{L}$ broth and stood still for $3 \mathrm{~h}$ at $37^{\circ} \mathrm{C}$. Then, the cell culture was spread onto antibiotic-containing selective plates, and then, they were incubated overnight at $37^{\circ} \mathrm{C}$.

Agarose gel electrophoresis and restriction endonuclease cleavage. Agarose gel electrophoresis of DNA was done according to the standard method (15). Restriction enzymes were purchased from commercial suppliers and used according to the specifications of the suppliers. Plasmid DNA fragment size was estimated using $\lambda$-HindIII fragments as standards. The fragment sizes in nucleotide pairs were calculated from nucleotide sequence determined by Sanger et al. (23).

\section{RESULTS AND DISCUSSION}

\section{Characteristics of plasmids isolated}

Five hundred and sixty-one drug-resistant bacteria to six kinds of antibiotics were isolated from several composts. The presence of plasmid DNA was examined for each bacterium by rapid alkaline extraction procedure, followed by agarose gel electrophoresis. B. subtilis MI113 was transformed with each of the plasmids isolated. Actually, antibiotic-resistant transformants were obtained with the plasmids originated from strains CR6, CR42, CR59, CR73, and CR94, which contained two to eight kinds of plasmids. Each plasmid DNA was recovered from each transformant to identify drug-resistance plasmid. The results are shown in Fig. 1 and in Table 1. 


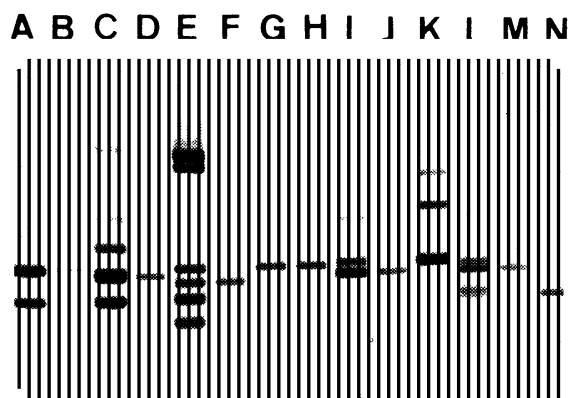

Fig. 1. Agarose gel electrophoresis of plasmid DNA. Lanes: A, plasmids from the strain CR6; B, pCS6 from transformant B. subtilis MI113; C, plasmids from the strain CR42; D, pES42 from transformant $B$. subtilis MI113; E, mixture of plasmids prepared from the strain CR59; F, pES59 from B. subtilis MI113; G, pCS59 from $B$. subtilis MI113; H, pTS59 from $B$. subtilis MI113; I, plasmids from the strain CR73; J, pES73 from B. subtilis MI113; K, pTS73 from B. subtilis MI113; L, plasmids from the strain CR 94; M, pES 94 from B. subtilis MI113; N, pC194 (2.9 kbp) (7). Electrophoresis was performed in $0.7 \%$ agarose gel.

Table 1. Resistance markers, size and unique restriction endonuclease cleavage sites of plasmids.

\begin{tabular}{|c|c|c|c|}
\hline Plasmid & Single cut enzymes & Drug resistance $^{a}$ & Size $(\mathrm{kbp})$ \\
\hline pCS6 & Eco RI, HindIII, Nsp V, SphI & $\mathrm{Cm}^{\mathrm{r}}$ & 4.6 \\
\hline pES42 & HincII, HpaI, NsiI, SacI, SphI, StyI & $\mathrm{Em}^{\mathrm{r}}$ & 4.3 \\
\hline pES59 & $\begin{array}{l}A c c \mathrm{I}, B_{a m \mathrm{HI},} E c o \mathrm{RI}, H i n \mathrm{dIII}, N s p \mathrm{~V}, S c a \mathrm{I}, \\
S p h \mathrm{I}, S t y \mathrm{I}, X b a \mathrm{I}\end{array}$ & $\mathrm{Em}^{\mathrm{r}}$ & 3.6 \\
\hline pCS59 & $A c c \mathrm{I}$, Nhe I, NspV, StyI,$X b a \mathrm{I}$ & $\mathrm{Cm}^{\mathrm{r}}$ & 4.7 \\
\hline pTS59 & $A c c \mathrm{I}, B a m \mathrm{HI}, E c o$ RI, $H p a \mathrm{I}, S p h \mathrm{I}, X b a \mathrm{I}$ & $\mathrm{Tc}^{\mathrm{r}}$ & 4.7 \\
\hline pES73 & $H i n c I I, H p a \mathbf{I}, N s i \mathrm{I}, S a c \mathrm{I}, S p h \mathrm{I}, S t y \mathbf{I}$ & $\mathrm{Em}^{\mathrm{r}}$ & 4.3 \\
\hline pTS73 & Eco RV, KpnI, NcoI, NsiI, StyI & $\mathrm{Tc}^{\mathrm{r}}$ & 4.8 \\
\hline pES94 & $H i n c \mathrm{II}, H p a \mathbf{I}, N s i \mathrm{I}, S a c \mathrm{I}, S p h \mathrm{I}, S t y \mathrm{I}$ & $\mathrm{Em}^{\mathrm{r}}$ & 4.3 \\
\hline
\end{tabular}

a $\mathrm{Cm}$ : chloramphenicol; Em: erythromycin; Tc: tetracycline.

Plasmid pCS6 isolated from the strain CR6 conferred chloramphenicol resistance to B. subtilis MI113 (Fig. 1, lane B). The copy number of this plasmid was suggested to be low from the weak intensity of the band in the agarose gel electrophoresis. As the low-copy plasmid in B. subtilis is rare and important for stable maintenance of cloned genes in an extrachromosomal state, this plasmid will be promising for developing a low-copy plasmid vector. Plasmids pES42 from CR 42 and pES94 from CR94 carried erythromycin-resistance gene (Fig. 1, lanes D, M). The strain CR73 was resistant to both erythromycin and tetracycline, coded on plasmid pES73 (Fig. 1, lane J), and on plasmid pTS73 (Fig. 1, lane K), respectively. From triple-resistant strain CR59, plasmids pES59 for erythromycin resistance, pCS59 for chloramphenicol resistance, and pTS59 for tetracycline resistance were isolated (Fig. 1, lanes F, G, H). As plasmids pCS59 and pTS59 had 
the similar molecular weight, they could not be distinguished from each other in the original strain CR59 (Fig. 1, lanes E, G, H).

Plasmids were digested with several restriction enzymes. Unique cleavage sites with several restriction endonucleases for each plasmid are summarized in Table 1. Cleavage sites with several restriction endonucleases for pCS59 were significantly different from those of pTS59, although the two plasmids look apparently the same as shown in Fig. 1.

Plasmids pES42, pES73, and pES94 generated the same unique sites (Table 1), and their restriction endonuclease maps showed the same pattern (data not shown). They might be mobilized from an original strain by mobilizing-plasmid carrier like B. subtilis (natto) 3335 (13) because they were isolated from the same compost.

As these newly-isolated plasmids had more unique cutting sites of restriction endonucleases than well-known $\mathrm{pC194}$, they might work better as cloning vectors. As composting is a thermophilic degrading process of organic matter (17), aerobic thermo-resistant endo-spore-forming bacteria such as Bacillus sps. were thought to become one of dominant bacteria, resulting in isolation of several antibioticresistant plasmids which can replicate in $B$. subtilis strains.

Transformation of B. subtilis MI113 with plasmids isolated by competent cell method

Transformation frequencies of these plasmids for $B$. subtilis MI113 were determined in the comparison with pC194 (Table 2). Transformation frequencies of pES59 and pTS59 were nearly the same level as pC194, but others exhibited lower frequencies (Table 2).

Stability of the plasmids in B. subtilis MI113 was examined as follows. Each plasmid-carrying transformant was pre-cultured in the presence of appropriate antibiotics at $30^{\circ} \mathrm{C}$ for $16 \mathrm{~h}$, and the pre-cultures were innoculated in $\mathrm{L}$ medium without antibiotics. After about 20 generations of the cell growth under nonselective conditions, each culture was spread on L-agar plate after dilution. One hundred colonies were transferred by replica plating onto assay plates with and without drugs. The fractions of plasmid-carrying cells in the total population are

Table 2. Transformation of $B$. subtilis MI113 with plasmid DNA by competent cells method.

\begin{tabular}{lcc}
\hline Plasmid & $\begin{array}{c}\text { Transformants } \\
\text { per } \mu \text { g of DNA }\end{array}$ & $\begin{array}{c}\text { Transformation frequency } \\
\text { (transformants/viable cell) }\end{array}$ \\
\hline pCS6 & $3.6 \times 10^{2}$ & $5.3 \times 10^{-7}$ \\
pES42 & $5.0 \times 10^{2}$ & $7.3 \times 10^{-7}$ \\
pCS59 & $5.5 \times 10^{3}$ & $8.2 \times 10^{-6}$ \\
pES59 & $8.2 \times 10^{3}$ & $1.2 \times 10^{-5}$ \\
pTS59 & $7.4 \times 10^{3}$ & $1.1 \times 10^{-5}$ \\
pES73 & $1.5 \times 10^{2}$ & $2.6 \times 10^{-7}$ \\
pTS73 & $1.2 \times 10^{2}$ & $2.1 \times 10^{-7}$ \\
pES94 & $2.2 \times 10^{2}$ & $3.2 \times 10^{-7}$ \\
pC194 & $1.8 \times 10^{3}$ & $2.6 \times 10^{-5}$ \\
\hline
\end{tabular}


Table 3. Stability of plasmids in B. subtilis MI113.

\begin{tabular}{lcc}
\hline Plasmid & No. of generations $^{a}$ & $\begin{array}{c}\text { Plasmid carrier } \\
(\%)\end{array}$ \\
\hline pCS6 & 20 & 68 \\
pCS59 & 22 & 78 \\
pES59 & 23 & 100 \\
pTS59 & 22 & 100 \\
pES73 & 22 & 9 \\
pTS73 & 22 & 87 \\
\hline
\end{tabular}

a Cells were grown at $30^{\circ} \mathrm{C}$.

Table 4. Transformation of B. subtilis NB22 protoplasts by plasmid DNA.

\begin{tabular}{lccc}
\hline Plasmid & $\begin{array}{c}\text { No. of regenerated } \\
\text { protoplasts per ml }\end{array}$ & $\begin{array}{c}\text { No. of transformants } \\
\text { per } 10 \mu \text { of DNA }\end{array}$ & $\begin{array}{c}\text { Transformation frequency } \\
\text { per regenerant }\end{array}$ \\
\hline pCS6 & $1.4 \times 10^{7}$ & 27 & $1.9 \times 10^{-6}$ \\
pES42 & $1.4 \times 10^{7}$ & 37 & $2.6 \times 10^{-6}$ \\
pCS59 & $1.0 \times 10^{7}$ & 10 & $9.3 \times 10^{-7}$ \\
pES59 & $1.4 \times 10^{7}$ & 43 & $3.0 \times 10^{-6}$ \\
pTS59 & $1.1 \times 10^{7}$ & 51 & $4.6 \times 10^{-6}$ \\
pES73 & $1.0 \times 10^{7}$ & 26 & $2.4 \times 10^{-6}$ \\
pTS73 & $1.1 \times 10^{7}$ & 3 & $2.7 \times 10^{-7}$ \\
pES94 & $1.4 \times 10^{7}$ & 30 & $2.1 \times 10^{-6}$ \\
pC194 & $1.0 \times 10^{7}$ & 38 & $3.5 \times 10^{-6}$ \\
\hline
\end{tabular}

calculated as shown in Table 3. pES59 and pTS59 were maintained stably at $30^{\circ} \mathrm{C}$ among the plasmids tested, which is the optimum temperature for iturin production (19). As these plasmids transformed B. subtilis MI113 at high frequency and replicated stably, they can be used as vectors for $B$. subtilis.

\section{Protoplast transformation of $B$. subtilis NB22}

As the transformation of $B$. subtilis NB22 with plasmid DNA by compentent cell method was unsuccessful or significantly inefficient, protoplasts of $B$. subtilis NB22 were transformed with plasmids prepared from B. subtilis MI113. Antibiotic-resistant transformants were obtained with all the plasmids tested. Transformation frequencies of $B$. subtilis NB22 determined are shown in Table 4. The presence of plasmids in drug-resistant colonies was confirmed in agarose gel electrophoresis after the alkaline extraction treatment (data not shown). The stability of plasmids in this host strain was examined (Table 5) in the similar way as mentioned above. Plasmids pES59, pTS59, pTS73, and pCS6 were relatively stable even in the iturin producer B. subtilis $\mathrm{NB} 22$ at $30^{\circ} \mathrm{C}$.

Although transformation of these plasmids into B. subtilis NB22 was achieved, the number of transformants that appeared was too small to apply this method for genetic analyses, such as cloning experiments. Moreover, the result of each transformation was highly variable due to the difficulty of preparing protoplasts of 
Table 5. Stability of plasmids in B. subtilis NB22.

\begin{tabular}{lcc}
\hline Plasmid & No. of generations $^{a}$ & $\begin{array}{c}\text { Plasmid carrier } \\
(\%)\end{array}$ \\
\hline pCS6 & 24 & 84 \\
pCS59 & 24 & 26 \\
pES59 & 24 & 100 \\
pTS59 & 24 & 100 \\
pES73 & 22 & 15 \\
pTS73 & 22 & 91 \\
\hline
\end{tabular}

a Cells were.grown at $30^{\circ} \mathrm{C}$.

Table 6. Transformation of iturin producers with plasmids.

\begin{tabular}{lllc}
\hline & & \multicolumn{2}{c}{ Transformants/ $\mu$ g DNA } \\
\cline { 2 - 4 } Strain & Plasmid & KCl-treatment & Electroporation \\
\hline NB22 & pCS6 & $2.0 \times 10$ & $8.8 \times 10^{5}$ \\
NB22 & pCS59 & $2.6 \times 10^{2}$ & $9.0 \times 10^{5}$ \\
NB22 & pES42 & 0 & $7.8 \times 10^{4}$ \\
NB22 & pES59 & $1.3 \times 10^{2}$ & $2.2 \times 10^{6}$ \\
NB22 & pTS59 & $1.6 \times 10^{2}$ & $1.3 \times 10^{6}$ \\
YB8 & pC194 & $4.1 \times 10^{3}$ & $1.6 \times 10^{6}$ \\
YB8 & pCS6 & $3.6 \times 10^{2}$ & $2.1 \times 10^{4}$ \\
YB8 & pCS59 & $2.4 \times 10^{3}$ & $2.2 \times 10^{4}$ \\
YB8 & pES42 & 6 & $9.7 \times 10^{3}$ \\
YB8 & pES59 & $1.2 \times 10^{3}$ & $9.3 \times 10^{4}$ \\
YB8 & pTS59 & $6.6 \times 10$ & $3.6 \times 10^{4}$ \\
UB24 & pC194 & $4.0 \times 10^{3}$ & $1.0 \times 10^{5}$ \\
UB24 & pCS6 & 0 & $2.5 \times 10^{4}$ \\
UB24 & pCS59 & 0 & $2.7 \times 10^{4}$ \\
UB24 & pES42 & 0 & $1.3 \times 10^{4}$ \\
UB24 & pES59 & $2.2 \times 10^{2}$ & $2.3 \times 10^{5}$ \\
UB24 & pTS59 & $2.7 \times 10^{2}$ & $1.2 \times 10^{5}$ \\
RB14 & pC194 & $2.1 \times 10^{3}$ & $3.9 \times 10^{5}$ \\
RB14 & pCS6 & 0 & $1.4 \times 10^{4}$ \\
RB14 & pCS59 & 0 & $5.1 \times 10^{3}$ \\
RB14 & pES42 & 0 & $4.3 \times 10^{3}$ \\
RB14 & pES59 & $5.0 \times 10$ & $2.2 \times 10^{3}$ \\
RB14 & pTS59 & 0 & $1.8 \times 10^{5}$ \\
\hline & pC194 & $1.7 \times 10^{3}$ & $6.8 \times 10^{4}$ \\
\hline
\end{tabular}

the cells of this bacterium. The transformed cells formed extremely mucoid colonies on regeneration medium, which spread over the surface of the plates, interfering with neighboring colonies. This made colony counting and replica plating difficult.

\section{Transformation by $\mathrm{KCl}$-method and electroporation}

To circumvent the problem mentioned above, transformation of vegetative cells of $B$. subtilis NB22 was then investigated by the $\mathrm{KCl}$-treatment method we 
have reported previously (2). Among 6 plasmids tested, 5 plasmids except for pES 42 were introduced into the cells of $B$. subtilis NB22 (Table 6). When this method was applied to other iturin producer $B$. subtilis YB8, this procedure gave transformants with almost equivalent efficiency to that of NB22. However, the efficiency for UB24 and RB14 was significantly lower. As an alternative method for the $\mathrm{KCl}$ method, electroporation of intact cells was applied, mainly because this method is especially useful for bacteria where existing DNA transfer methods are not known, or remarkably inefficient $(5,6,16)$. Electroporation also has the advantage especially when direct cloning of ligated DNA into the recipient strain was attempted as has been demonstrated $(5,22)$. All the iturin producers were successfully electroporated with newly-isolated plasmids as well as a reference plasmid pC194 (Table 6). No colonies were observed on selective plates on which the bacteria with control treatments (omission of the plasmid or pulse) were plated.

Although intensive work has been carried out on the biochemistry of peptide antibiotics, there is little knowledge of their genetics (12). The antibiotic iturin can be a model for the study of secondary metabolism because of its unique structure and its broad suppressibility to phytopathogens $(19,20)$. One important limiting factor in genetic studies with iturin producers has been the lack of efficient, rapid, and reliable techniques for introducing exogenous DNA into cells, especially into wild strains. Since iturin-producing B. subtilis and MI113 are distantly related because of the clear differences in their colony morphology, ability of competency, and the production of antibiotics, electroporation was found to be an efficient, simple, and reliable method for introducing plasmids into wild iturin producers.

Structural instability of plasmids in $B$. subtilis (in comparison to $E$. coli) is often observed (8), and one possible mechanism of the instability is thought to be the accumulation of high-molecular-weight (HMW) plasmid multimers (9). Further characterization of the newly-isolated plasmids such as HMW-multimer formation will be investigated in future. As the transformation method by new vector plasmids described here can be applied effectively to iturin producers, the regulation of the antibiotic production at the level of gene expression can be investigated efficiently.

\section{REFERENCES}

1) Anagnostopoulos, C. and Spizizen, J., Requirements for transformation in Bacillus subtilis. J. Bacteriol., 81, 741-746 (1961).

2) Ano, T., Kobayashi, A., and Shoda, M., Transformation of Bacillus subtilis with the treatment by alkali cations. Biotechnol. Lett., 12, 99-104 (1990).

3) Birnboim, H. C. and Doly, J., A rapid alkaline extraction procedure for screening recombinant plasmid DNA. Nucleic Acids Res., 7, 1513-1523 (1979).

4) Chang, S. and Cohen, S. N., High frequency transformation of Bacillus subtilis protoplasts by plasmid DNA. Mol. Gen. Genet., 168, 111-115 (1979).

5) David, S., Simons, G., and Vos, W. M., Plasmid transformation by electroporation of Leuconostoc paramesenteroides and its use in molecular cloning. Appl. Environ. Microbiol., 55, 1483-1489 
(1989)

6) Dunny, G. M., Lee, L. N., and LeBlanc, D. J., Improved electroporation and cloning vector system for gram-positive bacteria. Appl. Environ. Microbiol., 57, 1194-1201 (1991).

7) Ehrlich, S. D., Replication and expression of plasmids from Staphylococcus aureus in Bacillus subtilis. Proc. Natl. Acad. Sci. U.S.A., 74, 1680-1682 (1977).

8) Ehrlich, S. D., Noirot, P., Petit, M. A., Janniere, L., Michel, B., and te Riele, H., Structural instability of Bacillus subtilis plasmids. In Genetic Engineering, Vol. 8., ed. by Setlow, I. K. and Hollander, A., Plenum Press, New York (1986), p. 71-83.

9) Gruss, A. and Ehrlich, S. D., Insertion of foreign DNA into plasmids from gram-positive bacteria induces formation of high-molecular-weight plasmid multimers. J. Bacteriol., 170, 1183-1190 (1988).

10) Imanaka, T., Tanaka, T., Tsunekawa, H., and Aiba, S., Cloning of the genes for penicillinase, penP and penI, of Bacillus licheniformis in some vector plasmids and their expression in Escherichia coli, Bacillus subtilis, and Bacillus licheniformis. J. Bacteriol., 147, 776-786 (1981).

11) Isogai, A., Takayama, S., Murakoshi, S., and Suzuki, A., Structures of $\beta$-amino acids in antibiotics iturin A., Tetrahedron Lett., 23, 3065-3068 (1982).

12) Kleinkauf, H. and Döhren, H. V., Biosynthesis of peptide antibiotics. Annu. Rev. Microbiol., 41, 259-289 (1987).

13) Koehler, T. M. and Thorne, C. B., Bacillus subtilis (natto) plasmid pLS20 mediates interspecies plasmid transfer. J. Bacteriol., 169, 5271-5278 (1987).

14) Matsuno, Y., Ano, T., and Shoda, M., High-efficiency transformation of Bacillus subtilis NB22, an antifungal antibiotic iturin producer, by electroporation. J. Ferment. Bioeng., 73, 261-264 (1992).

15) Maniatis, T., Fritsch, E. F., and Sambrook, J., Molecular Cloning: A Laboratory Manual, Cold Spring Harbor Laboratory Press, Cold Spring Harbor, New York (1982).

16) Miller, J. F., Dower, W. J., and Tompkins, L. S., High-voltage electroporation of bacteria: genetic transformation of Campylobacter jejuni with plasmid DNA. Proc. Natl. Acad. Sci. U.S.A., 85, 856860 (1988).

17) Nakasaki, K., Shoda, M., and Kubota, H., Effect of temperature on composting of sewage sludge. Appl. Environ. Microbiol., 50, 1526-1530 (1985).

18) Peypoux, F., Guinand, M., Michel, G., Delcambe, L., Das, B. C., and Lederer, E., Structure of iturin A, a peptidolipid antibiotic from Bacillus subtilis. Biochemistry, 17, 3992-3996 (1978).

19) Phae, C. G., Shoda, M., and Kubota, H., Suppressive effect of Bacillus subtilis and its products to phytopathogenic microorganisms. J. Ferment. Bioeng., 69, 1-7 (1990).

20) Phae, C. G., Sasaki, M., Shoda, M., and Kubota, H., Characteristics of Bacillus subtilis isolated from composts suppressing phytopathogenic microorganisms. Soil Sci. Plant Nutr., 36, 575-586 (1990).

21) Phae, C. G. and Shoda, M., Expression of the suppressive effect of Bacillus subtilis on phytopathogens in inoculated composts. J. Ferment. Bioeng., 70, 409-414 (1990).

22) Powell, I. B., Achen, M. G., Hiller, A. J., and Davidson, B. E., A simple and rapid method for genetic transformation of lactic streptococci by electroporation. Appl. Environ. Microbiol., 54, 655-660 (1988).

23) Sanger, F., Coulson, A. R., Hong, G. F., Hill, O. F., and Petersen, G. B., Nucleotide sequence of bacteriophage $\lambda$ DNA. J. Mol. Biol., 162, 729-773 (1982).

24) Winkelmann, G., Allagaier, H., Lupp, R., and Jung, G., Iturin $A_{L}-A$ new long chain iturin $A$ possessing an unusual high content of $\mathrm{C}_{16}-\beta$-amino acids. J. Antibiot., 36, 1451-1457 (1983). 